\title{
Infection of Nicotiana benthamiana Plants with Potato Virus X (PVX) \\ Emmanuel Aguilar ${ }^{1}$, Francisco J. del Toro ${ }^{1}$, Bong-Nam Chung ${ }^{2}$, Tomás Canto ${ }^{1}$ and Francisco Tenllado ${ }^{1, *}$
}

\author{
${ }^{1}$ Department of Environmental Biology, Centro de Investigaciones Biológicas (CIB-CSIC), Madrid, Spain; \\ ${ }^{2}$ National Institute of Horticultural \& Herbal Science, Agricultural Research Center for Climate Change, \\ Jeju Island, South Korea \\ *For correspondence: tenllado@cib.csic.es
}

\begin{abstract}
[Abstract] Potato Virus $X(\mathrm{PVX})$ is the type member of Potexvirus genus, a group of plant viruses with a positive-strand RNA genome ( $6.4 \mathrm{~kb})$. PVX is able to establish compatible infections in Nicotiana benthamiana, a commonly used host in plant virology, leading to mild symptoms, such as chlorotic mosaic and mottling. PVX has been widely used as a viral vector for more than two decades (Chapman et al., 1992; Baulcombe et al., 1995; Aguilar et al., 2015). It provides a feasible means for the systemic expression in plants of heterologous proteins, such as avirulence factors, proteins with pharmacological properties, etc., (Hammond-Kosack et al., 1995; Gleba et al., 2014), and also as a tool to help decipher the function of genes in plants by virus-induced gene silencing (VIGS) (Lacomme and Chapman, 2008). Two different protocols, i.e., rubbing $(\mathrm{A})$ and agroinfiltration $(\mathrm{B})$, that allow efficient multiplication and propagation of $\mathrm{PVX}$ in $N$. benthamiana are described here in detail. The rubbing method requires previous infected sap, and infection is achieved by inducing mechanical damages to leaf tissue, allowing viral particles to penetrate the plant surface. Agroinfiltration needs previously modified agrobacterium to carry and deliver T-DNA with PVX sequences into the plant cell. Agrobacterium is grown until saturation and infection is established by infiltrating it into plant tissue with a syringe. Any of these two methods can be successfully applied, and the choice should be based mainly on the availability of material and time, but it is recommended to use agroinfiltration when chimeric viruses are being used.
\end{abstract}

Keywords: Potato Virus $X$, Inoculation, Agroinfiltration, Heterologous protein expression, Virus-induced gene silencing, Gene function

[Background] PVX is transmitted by mechanical means, so the easiest and fastest way to infect plants is by rubbing the leaves with sap from infected tissue. However, since RNA viruses have high mutation rates, caution must be taken when rubbing is used as propagation method. In this regard, the number of serial passages between plants should be limited, and the inoculum should be used fresh from original stocks. To solve this inconvenience, an infectious PVX cDNA clone has been introduced into a binary TDNA vector, which allows its easy delivery into $N$. benthamiana by Agrobacterium tumefaciens. Agroinfiltration should be considered as preferred method when recombinant PVX is being used, in order to prevent serial propagation of deleted viral forms from a previous experiment to the next one (Chung et al., 2007). 


\section{Materials and Reagents}

A. Rubbing

1. $2 \mathrm{ml}$ safe-lock tubes (Eppendorf, catalog number: 022363352 )

Note: This product has been discontinued.

2. Latex powder-free gloves (Staples, Ambitex ${ }^{\circledR}$, catalog number: SS2072105)

3. Gauze (Fisaude. Kinefis, catalog number: 10901)

4. N. benthamiana plants at the stage of 4-6 fully expanded true leaves (see Figure 1)

5. Flash frozen, infected tissue (PVX virus inoculum from DSMZ Plant Virus Collection, Reference No.: 15649, DSMZ No.: PV-0847, Leibniz Institute DSMZ-German Collection of Microorganisms and Cell Cultures)

6. Liquid nitrogen

7. Ice

8. Sodium dihydrogen phosphate $\left(\mathrm{NaH}_{2} \mathrm{PO}_{4}\right)$ (EMD Millipore, catalog number: 106346)

9. Di-sodium hydrogen phosphate $\left(\mathrm{Na}_{2} \mathrm{HPO}_{4}\right)$ (EMD Millipore, catalog number: 106559)

10. Abrasive carborundum powder (CARLO ERBA Reagents, catalog number: 434786)

11. Sodium phosphate buffer (see Recipes)

B. Agroinfiltration

1. Petri dishes (Gosselin, catalog number: BP93B-102)

2. $50 \mathrm{ml}$ conical centrifuge tubes (Corning, Falcon ${ }^{\circledR}$, catalog number: 352070 )

3. $13 \mathrm{ml}$ centrifuge tubes (SARSTEDT, catalog number: 62.515.006)

4. $1 \mathrm{ml}$ syringes, without needle (BD, catalog number: 309659$)$

5. $10 \mathrm{ml}$ sterile pipettes (Corning, Falcon ${ }^{\circledR}$, catalog number: 357551 )

6. N. benthamiana plants (at the 4-6 leaves stage, see Figure 1)

7. Agrobacterium tumefaciens (any disarmed strain, like GV3101) carrying a T-DNA binary vector with a full-length cDNA clone of PVX (Chapman et al., 1992; Lu et al., 2003, see Notes)

8. Agrobacterium tumefaciens (any disarmed strain, like GV3101) carrying the empty T-DNA binary vector, as control

9. Magnesium chloride $\left(\mathrm{MgCl}_{2}\right)$ (EMD Millipore, catalog number: 105833)

10. 2-morpholinoethanesulfonic acid (MES) (SERVA Serving Scientists, catalog number: 29834)

11. 3',5'-dimethoxy-4'-hydroxyaceto-phenone (Acetosyringone) (Sigma-Aldrich, catalog number: D134406)

12. Dimethyl sulfoxide (DMSO) (EMD Millipore, catalog number: 102952)

13. Tryptone (BD, Bacto ${ }^{T M}$, catalog number: 211705)

14. Yeast extract (Conda, catalog number: 1702)

15. Sodium chloride ( $\mathrm{NaCl}$ ) (EMD Millipore, catalog number: 106404)

16. American bacteriological agar (Conda, catalog number: 1802) 
17. Appropriate, selective antibiotics (Kanamycin and tetracycline) (Sigma-Aldrich, catalog numbers: K1377, 87128)

18. Induction buffer (see Recipes)

19. LB liquid medium supplemented with appropriate antibiotics (see Recipes)

20. LB/agar medium supplemented with appropriate antibiotics (see Recipes)

C. Western blot detection

1. $1.5 \mathrm{ml}$ safe-lock tubes (Eppendorf, catalog number: 0030120086)

2. Polyvinil PVDF membrane (GE Healthcare, catalog number:10600023)

3. Tris-hydroxymethyl-aminomethane (Tris) base (EMD Millipore, catalog number: 108386)

4. Hydrochloric acid $(\mathrm{HCl})$ (Hydrochloric acid 37\%) (EMD Millipore, catalog number: 100317)

5. Ethylenediaminetetraacetic acid (EDTA) (EMD Millipore, catalog number: 324503)

6. Lithium chloridue ( $\mathrm{LiCl}$ ) (EMD Millipore, catalog number: 105679)

7. $\beta$-mercaptoethanol solution (EMD Millipore, catalog number: 805740)

8. Sodium dodecyl sulfate (SDS) (EMD Millipore, catalog number: 817034)

9. Bromophenol Blue (BPB) (Sigma-Aldrich, catalog number: 114391)

10. Glycerol (Glycerol $87 \%$ solution) (EMD Millipore, catalog number: 104094)

11. 3-hydroxy-4-(2-sulfo-4-[4-sulfophenylazo] phenylazo)-2,7-naphthalenedisulfonic acid sodium salt (Ponceau S) (Sigma-Aldrich, catalog number: P3504)

12. Acetic acid (Acetic acid glacial $100 \%$ solution) (EMD Millipore, catalog number: 100063)

13. Sodium chloride ( $\mathrm{NaCl}$ ) (EMD Millipore, catalog number: 116224)

14. Potassium dihydrogen phosphate $\left(\mathrm{KH}_{2} \mathrm{PO}_{4}\right)$ (Sigma-Aldrich, catalog number: 60230)

15. Potassium chloride (KCl) (EMD Millipore, catalog number: 104936)

16. Acrylamide (30\% Acrylamide/Bis solution, 37.5:1) (Bio-Rad Laboratories, catalog number: 1610158)

17. Rabbit anti-PVX CP antibody (LOEWE Biochemica, catalog number: 07037)

18. Goat anti-rabbit antibody conjugated with AP (Sigma-Aldrich, catalog number: A3687)

19. SigmaFast ${ }^{\mathrm{TM}} \mathrm{BCI} / \mathrm{NBT}$ tablets (Sigma-Aldrich, catalog number: B5655)

20. Protein extraction buffer for Western blot (see Recipes)

21. $2 x$ Laemmli solution for western blot (see Recipes)

22. Ponceau S solution (see Recipes)

23. Blocking solution (see Recipes)

24. 10x PBS, pH 7.4 (see Recipes)

\section{Equipment}

A. Common equipment

1. Plant growth chambers (SANYO Electronic) at $24{ }^{\circ} \mathrm{C}, 2,500$ lux of daylight intensity, $16 \mathrm{~h} / 8 \mathrm{~h}$ day/night photoperiod 
2. P1000, P200 and P20 micropipettes (Gilson, Pipetman Classic ${ }^{\top M}$ )

B. Rubbing

1. Mortar and pestle (Silico \& Chemico Porcelain SE)

2. Refrigerated table microcentrifuge (Hettich Lab Technology, model: Mikro 200R)

3. Pacisa Weighing Balances (Precisa Gravimetrics, model: XB620C-G)

C. Agroinfiltration

1. $28{ }^{\circ} \mathrm{C}$ incubator for plate culture (JP Selecta, model: 2001258)

2. $28{ }^{\circ} \mathrm{C}$ refrigerated incubator shaker (Eppendorf, New Brunswick Scientific, model: 4330 )

3. Refrigerated centrifuge for $13 \mathrm{ml}$ tubes (Hettich Lab Technology, model: Universal 320R)

4. $600 \mathrm{~nm}$ wavelength-sensitive spectrophotometer (Eppendorf, model: Bio Photometer 6131 000.012)

D. Western blot detection

1. Blue polypropylene, pellet pestles for 1.5 Eppendorf tubes (Sigma-Aldrich, catalog number: Z359947)

2. Thermomixer (Eppendorf, catalog number: 5384000012)

3. Cork-borer set (Sigma-Aldrich, catalog number: Z165220)

\section{Procedure}

\section{A. Rubbing}

1. A tissue extract must be obtained from infected leaves. It is possible to use commercial viral inoculum as starting point (PVX from DMSZ, see Materials and Reagents). In the same way, PVX-infected tissue derived from plants that have been previously inoculated by mechanical means can be used. Tissue obtained from these plants at 7 days post-infection can efficiently initiate viral propagation. The plant tissue should come from the upper leaves of the plant, which usually show the most evident symptoms. Try to select the proximal part of the leaf because the virus infection front does not always reach the distal part. Discard the largest leaf vein (see Figure 1) 

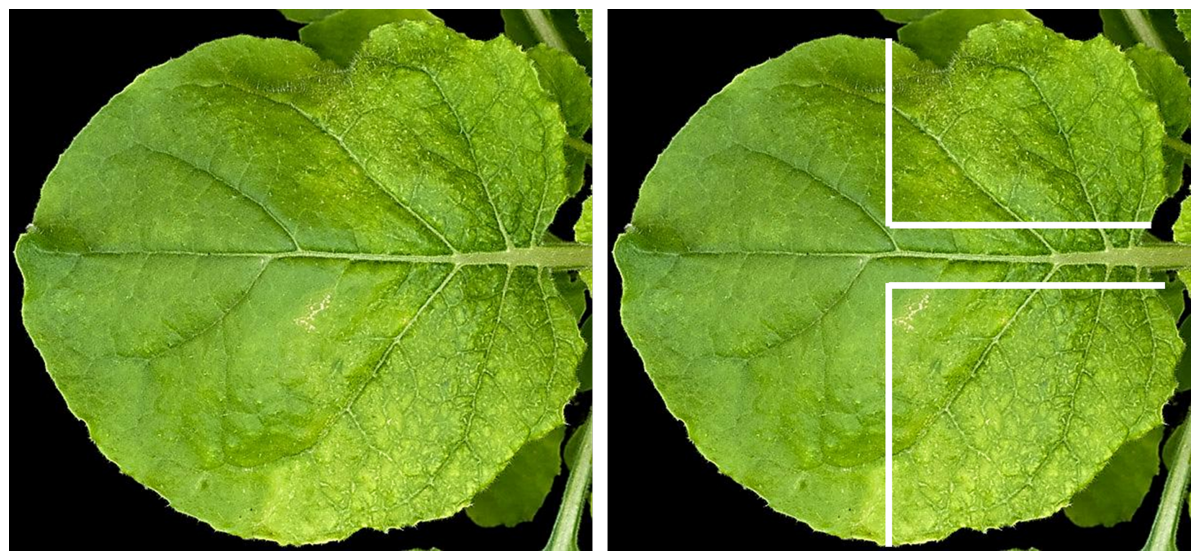

Figure 1. PVX-infected leaf showing symptoms at 7 days post-infection. Use as source material leaves with evident symptoms of infection (on the left). Try to select the proximal part of the leaf and discard the largest leaf vein (on the right, selected zones in white).

2. Collect tissue in aliquots of $300-400 \mathrm{mg}$. Take one aliquot and keep it into liquid nitrogen, and store the rest at $-80^{\circ} \mathrm{C}$. Discard tissue that has been previously defrosted.

3. Grind infected tissue with mortar and pestle refrigerated with liquid nitrogen. Try to obtain a fine powder.

4. Add 5 equivalents in volume of cold sodium phosphate buffer (see Recipes) to the powder while maintaining the mortar on ice (i.e., mixing $300 \mathrm{mg}$ of powdered tissue with $1.5 \mathrm{ml}$ of buffer). The components usually become frozen, so mix them with the pestle until a homogeneous, liquid mixture is obtained.

5. Take the extract mixture with a micropipette and put it into $2 \mathrm{ml}$ tubes. Use cut tips. Keep the mixture on ice to prevent degradation.

6. Centrifuge at $4{ }^{\circ} \mathrm{C}$ and $16,000 \times g$ for $5 \mathrm{~min}$.

7. Take the supernatant and discard the pellet. Put the supernatant into a new $2 \mathrm{ml}$ tube. Keep it on ice (for immediately use) or store at $-80^{\circ} \mathrm{C}$ (for long term use).

8. Select appropriate plants grown on long-day conditions. These plants must be at the stage of 4-6 fully expanded true leaves (see Figure 2) in order for the plant to become fully susceptible to virus infection. Dust with carborundum powder the entire adaxial surface of two fully expanded leaves (see Notes) per plant. The amount of carborundum should be enough as to observe it on the leaves. Follow the same procedure with all the selected plants. 


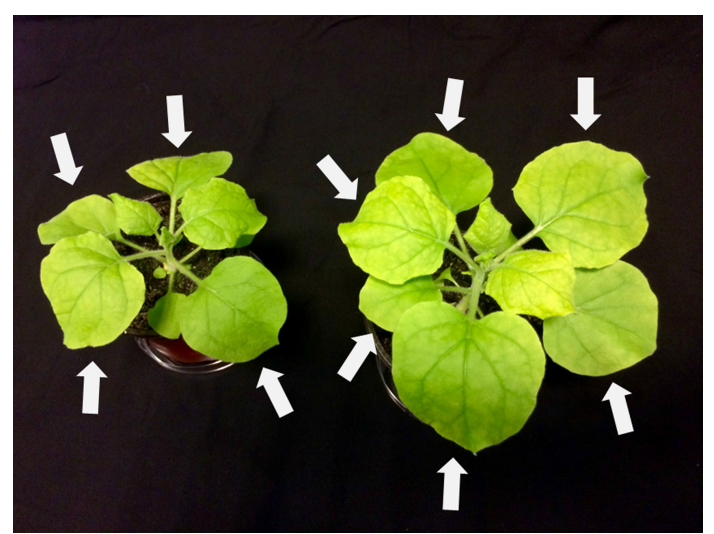

Figure 2. Nicotiana benthamiana plants. These plants must be at the stage of 4-6 fully expanded leaves in order for the plant to become fully susceptible to virus infection. White arrows point out leaves where rubbing is feasible.

9. Put viral extract on every carborundum-sprayed leaf of the entire pool of plants (see Figure 3). Place it directly with the pipette on the adaxial surface. Use $20 \mu \mathrm{l}$ of extract per selected leaf, adding $10 \mu \mathrm{l}$ per each half of leaf. Proceed immediately with the next step to avoid the evaporation of the extract.
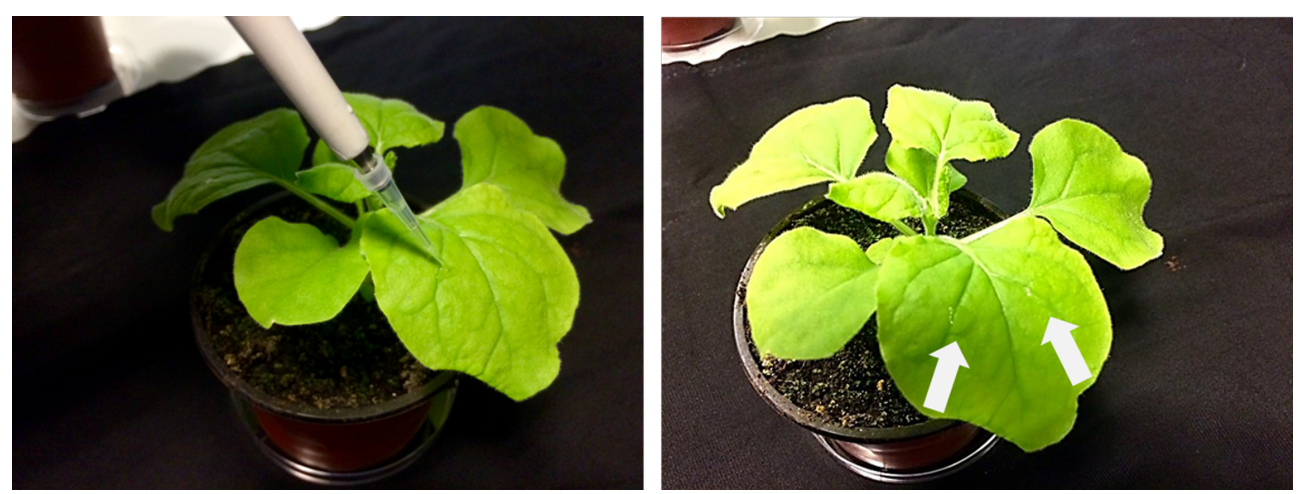

Figure 3. Delivery of viral extracts. Use $20 \mu \mathrm{l}$ of extract per selected leaf, adding $10 \mu \mathrm{l}$ per each half of leaf (on the left). Drops of viral extracts are marked with white arrows (on the right).

10. Every selected leaf must be rubbed carefully using latex gloves (see Figure 4). The leaf can be sustained by one hand while the other one is used for rubbing. Try not to press it, just only run the finger lightly over the surface about three times. Make sure the leaf is completely covered by the viral extract before starting with the next one (see Figure 5). 


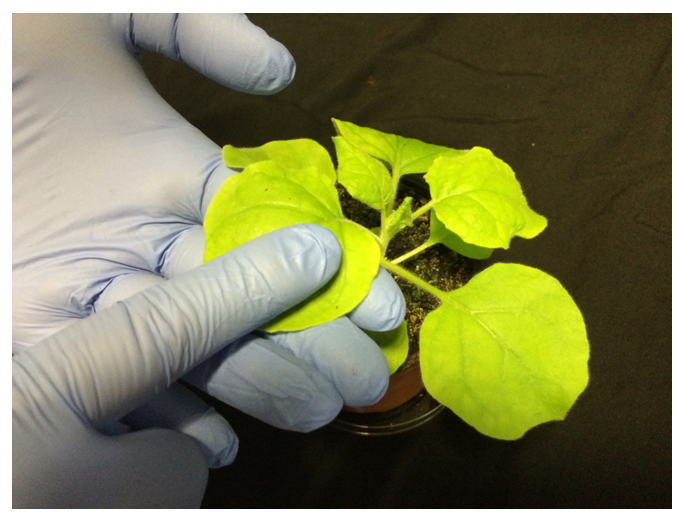

Figure 4. Rubbing. Every selected leaf must be rubbed carefully using latex gloves.
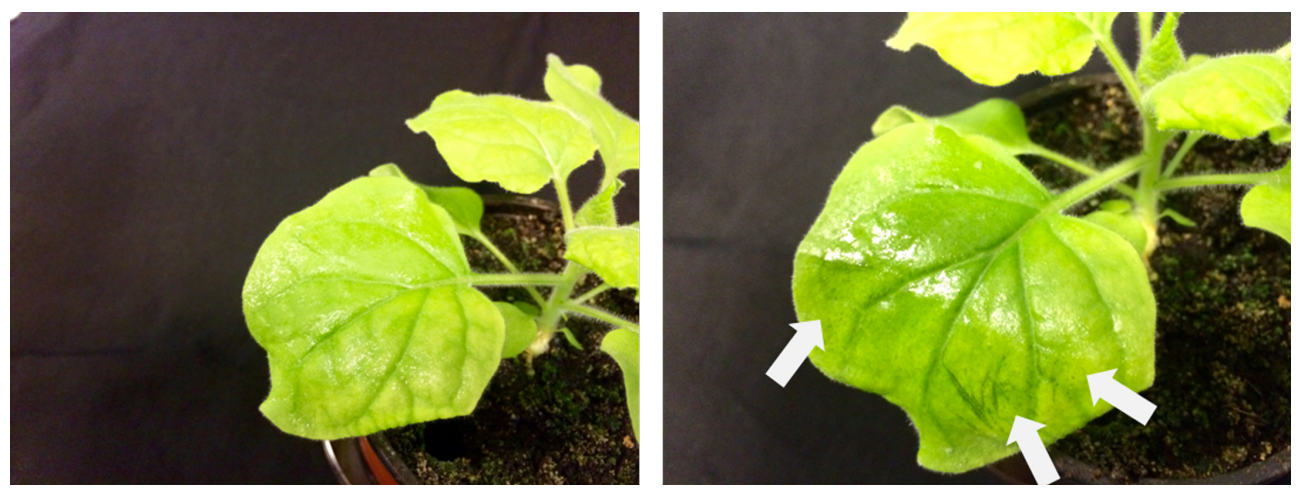

Figure 5. The leaf must be completely covered by the viral extract. The correct way (on the left) was made by rubbing it carefully; the wrong way (on the right, white arrows) produced injuries on the foliar surface after a while.

11. As a control group, inoculate the same number of plants with a tissue extract made from healthy plants following the same steps as the above. These plants are usually referred to as 'mock inoculated'. Change your gloves before proceeding. The number of plants depends on the experimental design. Although this protocol is highly successful, it is worth considering ten plants as the minimum representative sample size.

B. Agroinfiltration

1. Plate on LB/agar dishes the corresponding Agrobacterium constructs with appropriate selective antibiotics. Try to plate the bacteria 3 days before starting the experiment: this procedure ensures obtaining colonies with the proper age and higher growth rates in liquid medium (see next step).

2. Pick up a single colony and grow it overnight until saturation. Use $6 \mathrm{ml}$ of LB medium supplemented with appropriate antibiotics, in $50 \mathrm{ml}$ Falcon tubes, and fix one incubator shaker at $230 \mathrm{rpm}$ (revolutions per minute) and $28^{\circ} \mathrm{C}$.

3. Centrifuge a volume of saturated culture using $13 \mathrm{ml}$ tubes at 1,660 $\mathrm{g}$ for $10 \mathrm{~min}$. Discard the supernatant. This step does not require optical density measurements. 
4. Resuspend the agrobacterium pellet using induction buffer (see Recipes). Mix gently by pipetting until a homogeneous solution is obtained. It is advisable to use three volumes of induction buffer (i.e., 18-20 ml of induction buffer per pellet obtained from $6 \mathrm{ml}$ overnight culture).

5. Measure optical density at $600 \mathrm{~nm}$ wavelength $\left(\mathrm{OD}_{600}\right)$. It should be around $\mathrm{OD}_{600} \sim 1$

6. Different dilution degrees must be tried in order to achieve the correct one for your purpose. Make dilutions adding more induction buffer. $\mathrm{An}_{\mathrm{O}} \mathrm{D}_{600} \sim 0.2$ is enough to infect $N$. benthamiana.

7. Incubate the agrobacterium solution at room temperature, in a dark place, for $3 \mathrm{~h}$.

8. Use $1 \mathrm{ml}$ syringes without needle to infiltrate the solution through the abaxial surface of the leaf, while pushing with the index finger from the other side (see Figure 6). Infiltrate two fullyexpanded leaves per plant, using $0.5 \mathrm{ml}$ per each half of leaf (see Figure 7). This procedure makes possible the easy spread of virus infection from lower parts of the plant to the new emerging tissues. These plants must be at the stage of 4-6 fully expanded true leaves (see Figure 2), and they should be grown on long-day conditions.

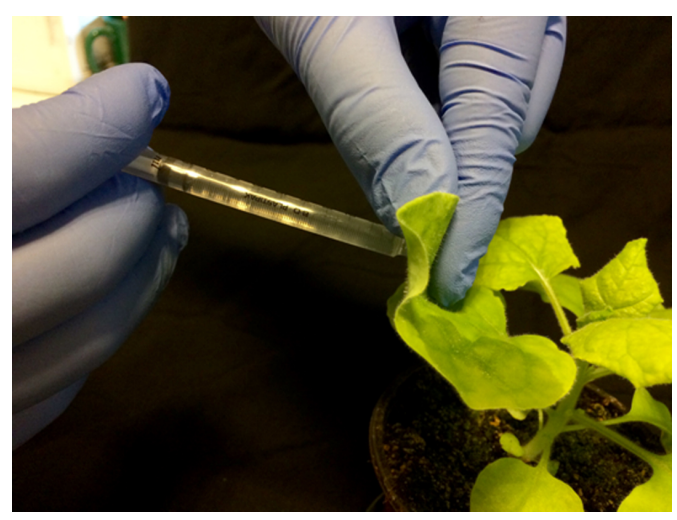

Figure 6. Agroinfiltration. Use $1 \mathrm{ml}$ syringes without needle to infiltrate the solution.

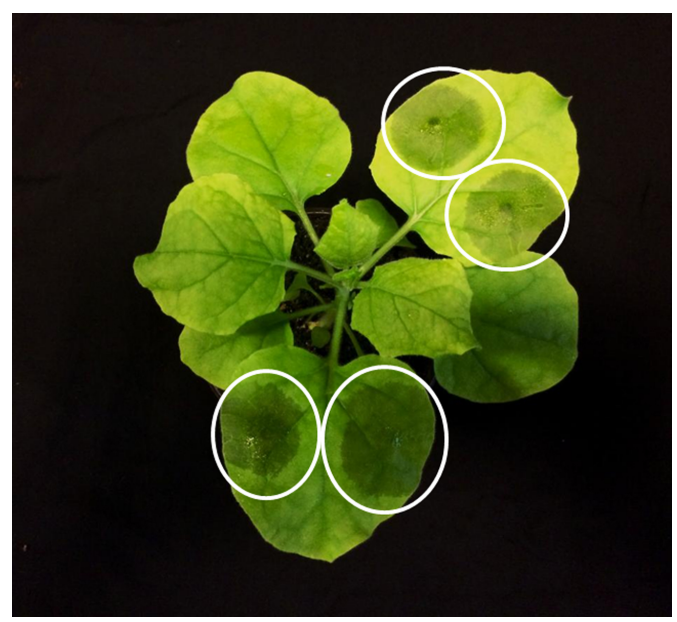

Figure 7. Infiltrate two fully expanded leaves per plant. Use $0.5 \mathrm{ml}$ per each half of leaf. Infiltrated areas are shown with white circles. 
9. Follow the same procedure to infiltrate the control group. The number of plants depends on the experimental design. Although this protocol is highly successful, it is worth considering ten plants as the minimum representative sample size.

\section{Data analysis}

Young plants infected with PVX can be easily distinguished from non-infected ones from 6 days after infection onwards by the naked eyes, but it could be more difficult when plants are infected at older stages. In addition, it would be interesting to check viral accumulation under different experimental conditions. So, it may be worth monitoring PVX through Western blotting, using antibodies against the PVX coat protein (CP). Briefly:

1. Take $100 \mathrm{mg}$ of infected systemic tissue and put it into $1.5 \mathrm{ml}$ tubes in liquid nitrogen. It is easier to collect four leaf discs using a cork-borer with a $15 \mathrm{~mm}$-diameter. Follow the same procedure with healthy controls.

2. Add $400 \mu$ l of protein extraction buffer (see Recipes) and homogenize using blue, polypropylene, pellet pestles.

3. Take $50 \mu \mathrm{l}$ of the homogenized solution and mix well with $50 \mu \mathrm{l}$ of $2 \mathrm{x}$ Laemmli solution (see Recipes). Boil samples at $95{ }^{\circ} \mathrm{C}$ for 3-5 min using a Thermomixer, and centrifuge them at maximum speed for $5 \mathrm{~min}$.

4. Use $16 \mu$ l of the supernatant to run an SDS-PAGE electrophoresis; any protocol for SDS-PAGE can be successfully applied (Aguilar et al., 2015). Resolve proteins in 15\% SDS-polyacrylamide gels, because PVX CP protein is around $25 \mathrm{kDa}$ of molecular weight. Transfer proteins from the gel to Hybond-P PVDF membranes, and stain the blotted membrane with Ponceau $S$ solution (see Recipes) to detect Rubisco protein as loading control. Ponceau S staining can be easily achieved by incubating the membrane with the solution and gentle shaking for five minutes. Before proceeding with the next step, de-stain the membrane by cleaning it with water and gentle shaking for five minutes.

5. Incubate the membrane for $2 \mathrm{~h}$ at room temperature with blocking solution (see Recipes), and subsequently incubate overnight with rabbit anti-PVX CP antibody diluted 1/400 in blocking solution, at room temperature. The next day, incubate with a secondary anti-rabbit APconjugated antibody diluted $1 / 10,000$ in blocking solution, for $1 \mathrm{~h}$ at room temperature. Finally, develop with BCIP/NBT tablet system based on alkaline phosphatase-mediated chromogenic reaction following manufacturer procedure. 


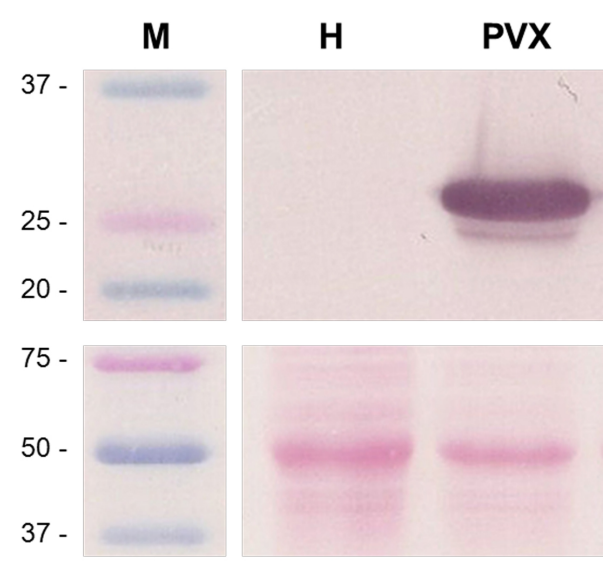

Figure 8. Western blot of PVX-infected plants at 7 days post-agroinfiltration. This figure shows three non-contiguous lines belonging to the same Western blot, with M: Molecular weight markers (kDa), H: Healthy plant extracts, and PVX: PVX-infected plant extracts. The upper panel shows the result for anti-PVX CP antibody incubation and BCIP/NBT chromogenic reaction. The lower panel shows the blotted, Ponceau S-stained membrane prior to antibody incubation, for Rubisco protein detection as loading control.

\section{$\underline{\text { Notes }}$}

1. pGR107 (Chapman et al., 1992; Lu et al., 2003) is a commonly used binary vector that originated from Prof. D. C. Baulcombe group, harboring an infectious PVX cDNA clone that contains an additional $\mathrm{CP}$ promoter and a polylinker, making it possible to insert foreign sequences.

2. Viral symptoms start to be noticeable around 4 days after inoculation (dai), reaching a maximum between 6-8 dai. Symptoms start to disappear one week after the first date of appearance, a phenomenon known as 'recovery'.

3. To apply the rubbing method, fill a $50 \mathrm{ml}$ tube with carborundum and cover it with 2-3 layers of gauze. This 'homemade' system allows for its appropriate delivery.

4. To apply the rubbing method, it is important to use the same kind of gloves and to follow the same rubbing patterns in order to achieve reproducibility.

\section{$\underline{\text { Recipes }}$}

1. Sodium phosphate buffer

$20 \mathrm{mM} \mathrm{NaH}_{2} \mathrm{PO}_{4} / \mathrm{Na}_{2} \mathrm{HPO}_{4}, \mathrm{pH} 7.0$

2. Induction buffer $(100 \mathrm{ml})$

$1 \mathrm{ml} \mathrm{MgCl} 2$ stock solution (final: $10 \mathrm{mM} \mathrm{MgCl}_{2}$ )

$1 \mathrm{ml}$ MES stock solution (final: $10 \mathrm{mM}$ MES)

$150 \mu \mathrm{l}$ acetosyringone stock solution (final: $150 \mu \mathrm{M}$ acetosyringone)

Complete to a final volume of $100 \mathrm{ml}$ with sterilized double distilled water 
Stock solutions:

$1 \mathrm{M} \mathrm{MgCl}_{2}$ (Magnesium chloride)

1 M MES (2-morpholinoethanesulfonic acid) buffer, pH 5.7

$100 \mathrm{mM}$ acetosyringone (3',5'-dimethoxy-4'-hydroxyaceto-phenone), dissolved in DMSO (Dimethyl sulfoxide)

3. Luria Broth medium (LB medium), $\mathrm{pH} 7.0$

$1 \%(w / v)$ tryptone

$0.5 \%(\mathrm{w} / \mathrm{v})$ yeast extract

$1.0 \%(\mathrm{w} / \mathrm{v}) \mathrm{NaCl}$

4. LB/agar medium

$\mathrm{LB}+1.5 \%(\mathrm{w} / \mathrm{v})$ agar

5. Protein extraction buffer for Western blot

$0.1 \mathrm{M}$ Tris- $\mathrm{HCl}, \mathrm{pH} 8.0$

10 mM EDTA

$0.1 \mathrm{M} \mathrm{LiCl}$

$1 \%(\mathrm{v} / \mathrm{v}) \beta$-mercaptoethanol

$1 \%(w / v)$ SDS

Stock solutions:

$1 \mathrm{M}$ Tris- $\mathrm{HCl}$ (tris-hydroxymethyl-aminomethane and hydrochloric acid), $\mathrm{pH} 8.0$

$0.5 \mathrm{M}$ EDTA (ethylenediaminetetraacetic acid), $\mathrm{pH} 8.0$

$20 \%$ SDS (sodium dodecyl sulfate) solution

6. 2x Laemmli solution for Western blot

$4 \%(w / v)$ SDS

$2 \%(v / v) \beta$-mercaptoethanol

$0.1 \mathrm{M}$ Tris- $\mathrm{HCl}, \mathrm{pH} 6.8$

$0.05 \%(w / v)$ BPB powder reagent

$20 \%(\mathrm{v} / \mathrm{v})$ glycerol

Stock solution:

$1 \mathrm{M}$ Tris- $\mathrm{HCl}$ (tris-hydroxymethyl-aminomethane and hydrochloric acid), $\mathrm{pH} 6.8$

7. Ponceau $\mathrm{S}$ solution

$0.1 \% \mathrm{w} / \mathrm{v}$ Ponceau $\mathrm{S}$ powder reagent

$5 \% \mathrm{v} / \mathrm{v}$ acetic acid solution

8. Blocking solution

$5 \% \mathrm{w} / \mathrm{v}$ skimmed milk powder

$10 \mathrm{mM}$ 1x PBS buffer

Stock solution:

10x PBS (phosphate-buffered saline), pH 7.4

9. 10x PBS, pH $7.4(1 \mathrm{~L})$

$80 \mathrm{~g} \mathrm{NaCl}$ (sodium chloride) 
$2.0 \mathrm{~g} \mathrm{KCl}$ (potassium chloride)

$14.4 \mathrm{~g} \mathrm{Na}_{2} \mathrm{HPO}_{4}$ (sodium dihydrogen phosphate)

$2.4 \mathrm{~g} \mathrm{KH}_{2} \mathrm{PO}_{4}$ (potassium dihydrogen phosphate)

Complete to a final volume of $1 \mathrm{~L}$ with sterilized double distilled water

\section{Acknowledgments}

This protocol was developed and optimized for the T-DNA binary vector pGR107 by modifying the procedure used for pGR106 (Lu et al., 2003). E.A. is recipient of a FPU fellowship from the former Spanish Ministry of Education and Sport. This work was supported by the Spanish Ministry of Economy and Competitiveness (Grant Ref. BIO2013-47940-R); The Rural Development Administration (RDA) of the Republic of Korea (Grant Refs. PJ00946102; PJ010246).

\section{$\underline{\text { References }}$}

1. Aguilar, E., Allende, L., Del Toro, F. J., Chung, B. N., Canto, T. and Tenllado, F. (2015). Effects of elevated $\mathrm{CO}_{2}$ and temperature on pathogenicity determinants and virulence of potato virus X/potyvirus-associated synergism. Mol Plant Microbe Interact 28(12): 1364-1373.

2. Baulcombe, D. C., Chapman, S. and Santa Cruz, S. (1995). Jellyfish green fluorescent protein as a reporter for virus infections. Plant J. 7:1045-1053.

3. Chapman, S., Kavanagh, T. A. and Baulcombe, D. C. (1992). Potato virus X as a vector for gene expression in plants. Plant J. 2: 549-557.

4. Chung, B. N., Canto, T. and Palukaitis, P. (2007). Stability of recombinant plant viruses containing genes of unrelated plant viruses. J Gen Virol 88(Pt 4): 1347-1355.

5. Gleba, Y. Y., Tusé, D., and Giritch, A. (2014). Plant viral vectors for delivery by Agrobacterium. Curr Top in Microbiol Immunol 375: 155-192.

6. Hammond-Kosack, K. E., Staskawicz, B. J., Jones, J. D. G. and Baulcombe, D. C. (1995). Functional expression of a fungal avirulence gene from a modified potato virus $\mathrm{X}$ genome. $\mathrm{Mol}$ Plant-Microbe Interact 8: 181-185.

7. Lacomme, C. and Chapman, S. (2008). Use of potato virus $X(P V X)$-based vectors for gene expression and virus-induced gene silencing (VIGS). Curr Protoc Microbiol. Chapter 16: Unit $16 \mid 1$.

8. Lu, R., Malcuit, I., Moffett, P., Ruiz, M. T., Peart, J., Wu, A. J., Rathjen, J. P., Bendahmane, A., Day, L. and Baulcombe, D. C. (2003). High throughput virus-induced gene silencing implicates heat shock protein 90 in plant disease resistance. EMBO J 22(21): 5690-5699. 